E3S Web of Conferences 1, 02002 (2013)

DOI: $10.1051 / \mathrm{e} 3$ sconf/20130102002

(C) Owned by the authors, published by EDP Sciences, 2013

\title{
The application of passive sampler (DGT) technology for improved understanding of metal behaviour at a marine disposal site
}

\author{
$\underline{\text { R. Parker }}{ }^{1}$, T. Bolam ${ }^{1}$, S. Kröger ${ }^{1}$, C. Mason ${ }^{1}$, S. Birchenough ${ }^{1}$, B. Silburn ${ }^{1}$, D. Sivyer ${ }^{1}$, A. G. Mayes ${ }^{2}$ and G. R. Fones ${ }^{3}$ \\ ${ }^{1}$ Centre for Environment, Fisheries and Aquaculture Science, Lowestoft Laboratory, Pakefield Road, Lowestoft, Suffolk, \\ UK, NR33 0HT, ruth.parker@cefas.co.uk: thi.bolam@cefas.co.uk: silke.kroeger@cefas.co.uk: \\ claire.mason@cefas.co.uk: silvana.birchenough@cefas.co.uk: briony.silburn@cefas.co.uk: dave.sivyer@cefas.co.uk \\ ${ }^{2}$ Chemistry Department, University of East Anglia, Norwich, UK, andrew.mayes@ virgin.net \\ ${ }^{3}$ School of Earth and Environmental Sciences, University of Portsmouth, Burnaby Building, Burnaby Road, Portsmouth, \\ UK, PO1 3Q, gary.fones@port.ac.uk
}

\begin{abstract}
Metal behaviour and availability at a contaminated dredge material disposal site within UK waters has been investigated using Diffusive Gradient in Thin films (DGT) passive sampling technology. Three stations representing contrasting history and presence of maintenance dredge disposal, including a control station outside the disposal site, have been studied and depth profiles of fluxes of different metals (Fe, $\mathrm{Mn}, \mathrm{Pb}, \mathrm{Cu}, \mathrm{Cd}, \mathrm{Cr}, \mathrm{Ni}, \mathrm{Zn}$ ) to the binding gel (Chelex 100) have been derived. Higher flux rates and shallower mobilisation of metals ( $\mathrm{Mn}$ and $\mathrm{Fe}$ ) to the binding gel were observed at the disposal stations compared to the control station. Here we describe metal mobilization at different depths, linking the remobilization of $\mathrm{Fe}^{2+}$ and $\mathrm{Mn}^{2+}$ to the sediment (re)supply of other heavy metals of interest with a focus on $\mathrm{Cd}, \mathrm{Ni}$ and $\mathrm{Pb}$ and as they are on the Water Framework Directive (WFD) list of priority substances and OSPAR list of priority pollutants. Results showed that $\mathrm{Cd}, \mathrm{Pb}$ and $\mathrm{Ni}$ exhibited signs of resupply at the sediment-water interface (SWI). There was a potential increased mobilisation and source to the water column of $\mathrm{Pb}$ and $\mathrm{Ni}$ at the disposal site stations, but there was no $\mathrm{Cd}$ source, despite higher total loadings. This information has the potential to improve our current understanding of metal cycles at disposal sites. This work can be used as an indication of likely metal bioavailability and also assist in determining whether the sites act as sources or sinks of heavy metals. This information could assist disposal site monitoring and dredge material licensing.
\end{abstract}

Keywords: Dredge material, disposal, WFD, heavy metals, profiles, sediments, DGT

\section{Introduction}

There are approximately 150 sites designated for dredging disposal around the coast of England, with the majority of these located on the coast of the mainland, generally within a few miles of a major port or estuary entrance (Bolam et al., 2011). In total, approximately 40 million wet tones of dredged material are annually disposed of at these licensed sites, although not all of the sites are annually used. Monitoring associated with these disposal sites is carried out annually and includes a number of different contaminant parameters, such as tributyltin, polyaromatic hydrocarbons, organohalogens and trace metals measured as total metal concentrations in bulk sediments. There is also information collected as part of the monitoring to characterise the sediment status at these disposal sites. The monitoring is based on impact hypotheses, which are set up for addressing important questions. These are: i) what is the fate of contaminants (including metals) imported to the site with the disposed material and what effect does this have on ecological components? At present little is known regarding metal speciation or detailed vertical distribution and partitioning of metal contaminants within the sediments. The aim of this work was to apply DGT technology as a complementary tool to the routine monitoring conducted at Souter Point disposal site to provide an improved understanding of metal behaviour and fate.

\section{Materials and Methods}

Souter Point disposal site is located in the North East 


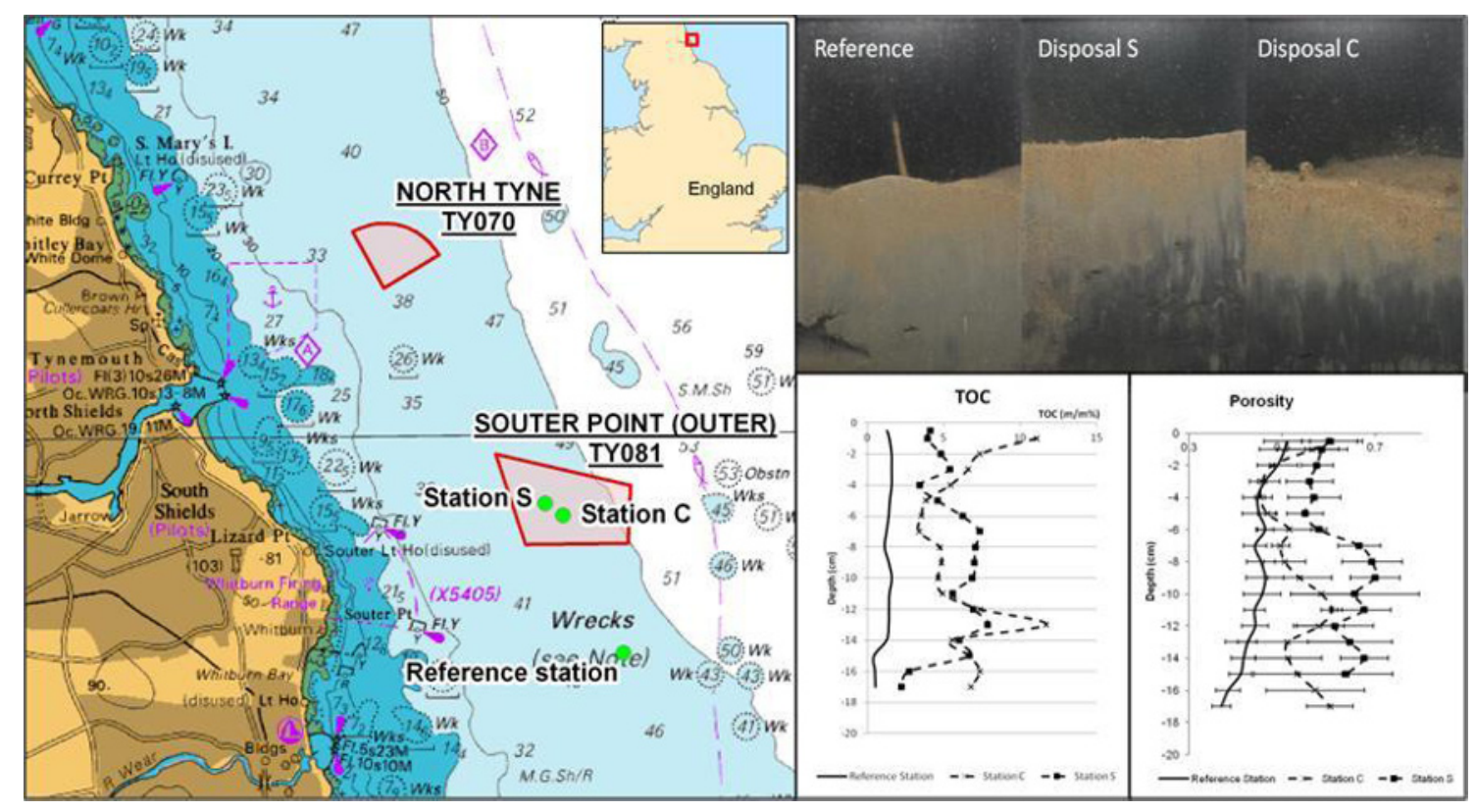

Fig.1 Souter Point sampling stations with Sediment Profile Imagery example images from the three stations and profiles of total organic carbon (TOC) and porosity

coast of the UK (Fig. 1). This site has been used for the disposal of dredged material since 1952 and selected stations have been monitored annually since the early 70's. This work summarises results obtained during a research cruise conducted in June 2011. Observations and measurements were made during the cruise and on recovered samples back at the laboratory.

Sampling approach: $0.1 \mathrm{~m}^{2}$ NIOZ box-cores were collected at 3 stations: (4 core replicates were collected from the Reference station, located south of the disposal site and 3 core replicates were taken from Station C and station $S$, both located within the disposal site (Figure 1). Sub-coring for DGT deployment was carried out before incubation of the sub-cores (these sub-cores were kept under dark and in aerated seawater). De-oxygenated DGT probes (Chelex and AgI) were deployed for between 24 and 35 hours and upon retrieval the probes were rinsed with Milli-Q water to remove excess sediment, stored in clean plastic bags and transferred back to the laboratory for analysis.

Analytical work: The DGT probes and procedural blanks were de-oxygenated in a $0.01 \mathrm{M} \mathrm{NaCl}$ overnight. The time and temperature were recorded at the deployment and retrieval points. Chelex gel: The gel was sliced at $0.5 \mathrm{~cm}$ resolution and eluted in $1 \mathrm{ml}$ of $1 \%$ $\mathrm{HNO} 3$ for 24 hours before analysis of $\mathrm{Cd}, \mathrm{Cr}, \mathrm{Cu}, \mathrm{Fe}, \mathrm{Mn}$, $\mathrm{Ni}, \mathrm{Pb}$ and $\mathrm{Zn}$ by ICP-MS and ICP-AES (Davison et al., 2000) AgI gel: The AgI gels were removed from the probes and covered with a hydrated plastic film. The gels were then scanned while wet in a flat-bed scanner. The greyscale intensity of the scanned images will be analysed with the software ImageJ. Using the calibration curve derived by Teasdale et al., 1999, total dissolved sulphides can be quantitatively measured in the gels.

Supporting measurements to complement the DGT probes were also collected. Oxygenation of the upper sediments layer was measured with oxygen pore water profiles obtained using oxygen microelectrodes (Unisense) using a method adapted from Rabouille et al., (2001). Sediment characteristics were derived from vertical slices of sub-cores at resolutions $0-0.5,0.5$ to $1 \mathrm{~cm}$ and then at $1 \mathrm{~cm}$ intervals and analysed for particle size, porosity, and total carbon. PSA analysis was derived using a method developed by Mason et al. (2011). Total carbon was analysed using the methodology developed by Verado et al. (1990).

\section{Results and Discussion}

A summary of station characteristics is shown in Table 1 and Figure 1 and DGT-Flux vertical profiles in Figure 2. All stations were composed of muddy sands. Porosity in the upper layers of the sediment at reference station was lowest (0.48) and elevated in the deeper sediment layers at the disposal stations. Total organic carbon was lowest at the reference station with higher carbons at the two disposal stations. The combined porosity and total organic carbon vertical profiles (Fig. 1) illustrated the difference between the reference station which showed a background decrease in porosity with depth and decreasing carbon. In contrast, the disposal stations exhibited complex porosity and carbon signatures 
Tab.1 Summary sediment characteristics of the three stations - average values for upper 0 to $5 \mathrm{~cm}$ with standard deviations in italics

\begin{tabular}{|l|l|l|l|l|l|l|l|l|l|l|}
\hline Station & $\begin{array}{l}\text { Sand } \\
(\%)\end{array}$ & $\begin{array}{l}\text { Silt/clay } \\
(\%)\end{array}$ & Porosity & $\begin{array}{l}\text { TOC } \\
(\% \mathrm{~m} / \mathrm{m})\end{array}$ & $\begin{array}{l}\text { OPD } \\
(\mathrm{cm})\end{array}$ & $\begin{array}{l}\mathrm{Fe} \\
(\mathrm{g} \\
/ \mathrm{kg})\end{array}$ & $\begin{array}{l}\mathrm{Mn} \\
(\mathrm{mg} \\
/ \mathrm{kg})\end{array}$ & $\begin{array}{l}\mathrm{Cd} \\
(\mathrm{mg} \\
/ \mathrm{kg})\end{array}$ & $\begin{array}{l}\mathrm{Ni} \\
(\mathrm{mg} / \\
\mathrm{kg})\end{array}$ & $\begin{array}{l}\mathrm{Pb} \\
(\mathrm{mg} / \\
\mathrm{kg})\end{array}$ \\
\hline Reference & 89 & 10 & $\begin{array}{l}0.48 \\
(0.05)\end{array}$ & 1.5 & $\begin{array}{l}0.5 \\
(0.2)\end{array}$ & 37 & 472 & $<\mathrm{LOD}$ & 51 & 110 \\
\hline Disposal S & 85 & 15 & $\begin{array}{l}0.57 \\
(0.03)\end{array}$ & 4.4 & $\begin{array}{l}0.4 \\
(0.2)\end{array}$ & 39 & 485 & 0.36 & 49 & 170 \\
\hline Disposal C & 83 & 16 & $\begin{array}{l}0.51 \\
(0.03)\end{array}$ & 6.9 & $\begin{array}{l}0.4 \\
(0.1)\end{array}$ & 36 & 493 & 0.37 & 47 & 157 \\
\hline
\end{tabular}

down-core related to disposal events. The heterogenous structure in vertical profiles illustrated the disposal events at the impacted stations. The oxygen penetration and profiles were similar for all the stations, with diffusion-type profiles and with oxygen consumed within the upper $1 \mathrm{~cm}$ of the sediment. The deeper redox conditions demonstrated by the SPI images using $\mathrm{Fe}^{3+}$ colour (Fig. 1) were deepest at the reference station, and shallowest at the disposal stations. The SPI images also showed the progression of sulphide formation lower in the sediments when compared to the reference station.

DGT metal fluxes were calculated for each deployed DGT probes at each station and the average flux profiles $( \pm \mathrm{sd})$ were plotted for each metal at the 3 stations (Fig. 2). The limits of quantification (LOQ) for each metal DGT analysis (24hr deployment) are $\left(\mathrm{ng} \mathrm{ml}^{-1}\right)$ : Cd; 0.073, Pb: 0.044, Ni: 0.086, Fe: 12.6, Mn: 0.214.

Fe and Mn: Fe and Mn profiles showed the start of sub-surface remobilisation at about $1-2 \mathrm{~cm}$ and $<1 \mathrm{~cm}$ respectively. Mn release occurs as oxygen was depleted within the upper centimetre of the sediment Fe showed a rapid increase of supply close to the surface at all stations and continued supply to depth. The rate of increase with depth in Fe flux at the disposal stations was greater than at the reference station. Fe showed continued supply to depth whilst Mn showed a subsurface peak. The supply rates for $\mathrm{Fe}$ and $\mathrm{Mn}$ at the disposal stations were higher than at the reference station. The Fe fluxes were 1 order of magnitude higher than $\mathrm{Mn}$ fluxes.

Cd: All 3 stations showed a peak of DGT available $\mathrm{Cd}$ at the SWI. Below the SWI, levels of Cd supply were low at all stations apart from distinct peaks of higher $\mathrm{Cd}$ supply at distinct depths $\left(0.1\right.$ to $\left.0.2 \mathrm{fmol} / \mathrm{cm}^{2} / \mathrm{s}\right)$. There was no trend of $\mathrm{Cd}$ release down core in any of the stations. The lack of difference in Cd supply between the reference and disposal stations would imply that Souter Point stations were not a significant source of $\mathrm{Cd}$ release into the pore-water, associated with material disposal.

$\mathrm{Pb}$ : Lead profiles showed increasing flux to the DGT gel down the station cores, with flux rate increasing in all stations in the deeper sediment layers. The fluxes at the reference station and at the disposal station $\mathrm{S}$ were similar, whilst disposal station $\mathrm{C}$ showed the highest fluxes (Fig. 2). The variance in $\mathrm{Pb}$ flux with depth was lower at the reference stations and highest at the disposal stations. This variance was similar to other metals, illustrating the complexity in metal cycles introduced by disposal operations. The background levels of particulate $\mathrm{Pb}$ were not highest at the disposal station $\mathrm{C}$, despite the highest supply rate. This discrepancy showed that controls of metal release could be complex and therefore cannot be determined from sediment metal content alone. Disposal station $\mathrm{C}$ in particular was a source of pore water $\mathrm{Pb}$ to the water column, in contrast to the reference and disposal station $\mathrm{S}$.

Ni: All 3 stations showed an increase in Ni supply to the gel in the upper parts of the sediment, with consistent supply rates with depths greater than $5 \mathrm{~cm}$. The overall supply of Ni throughout the profile at Disposal station $\mathrm{C}$ was higher than the other two stations. Profiles at all three stations indicated that dissolved $\mathrm{Ni}$ is removed from the water-column.

Metal availability and mobility can be closely linked to the amount of free sulphide ions in sediments. Deployment of AgI gel probes into the sediments cores revealed that free sulphide was at or below the limit of detection for the DGT based method evaluated through colour scanning. This correlated well with the high concentrations of free $\mathrm{Fe}$ and $\mathrm{Mn}$ ions observed in the metal profiles, as any free sulphide would have reacted with the $\mathrm{Fe}$ and $\mathrm{Mn}$ to form insoluble iron/manganese-sulfide complexes. Further investigation of the mechanisms controlling the sediment: pore-water supply of metals between the stations and with depth will be undertaken for the conference presentation. This analysis will include metal:metal flux and metal:carbon analysis with depth to illucidate controls in metal resupply.

\section{Conclusions}

This initial application of DGT technologies to disposal site metal behaviour has shown promising results. The metal behaviour at each of the stations has illustrated the clear advantages of using suite of different techniques to characterise metal station and with depth behaviour rather than bulk analysis alone. The metal profiles, rates of release and likely role of sediment disposal between stations showed different responses. 


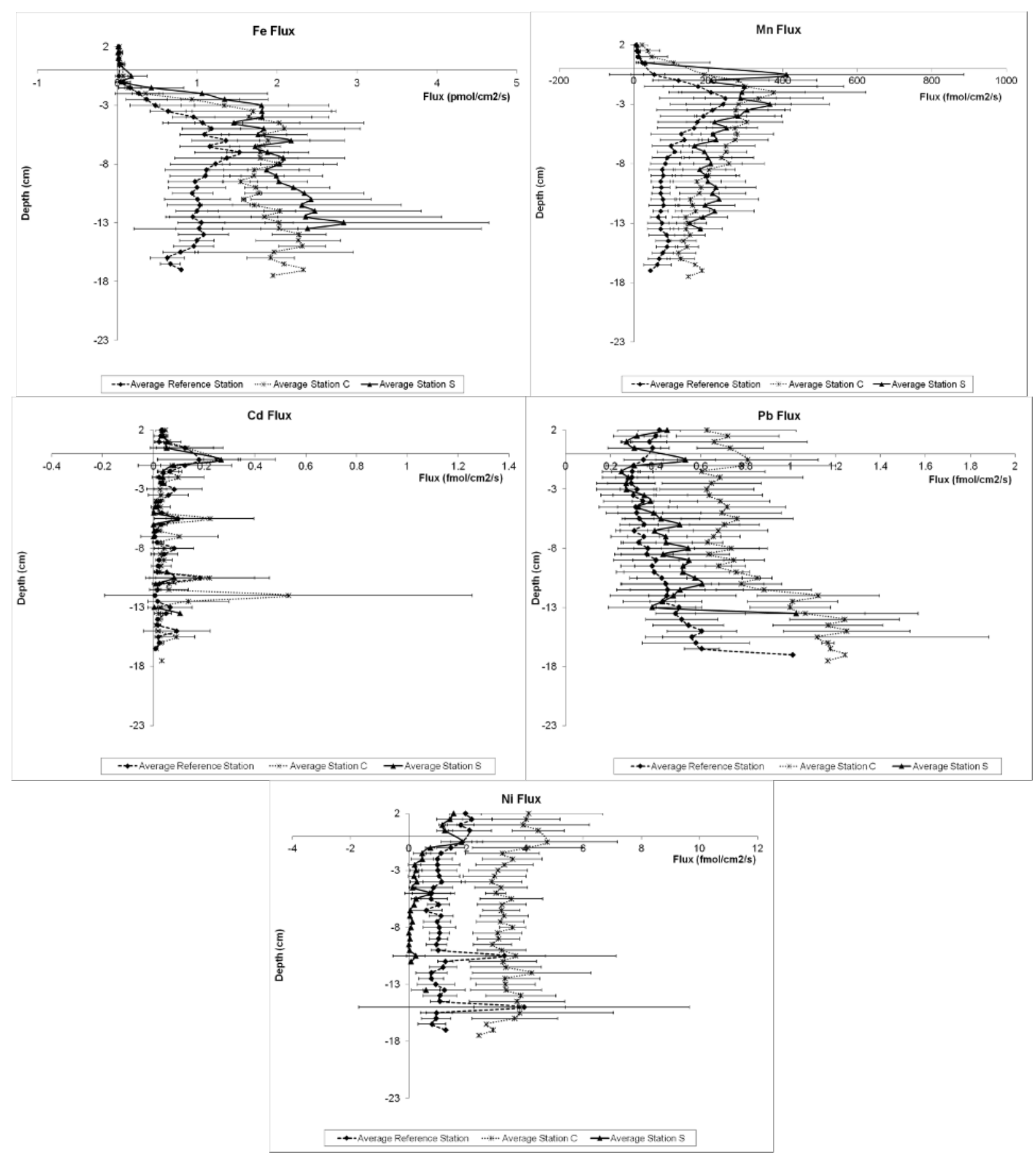

Fig.2 Metal profiles (flux into gel) from all three stations (Reference, Disposal C and Disposal S)

The increased release of $\mathrm{Pb}$ and $\mathrm{Ni}$ to the pore-waters at one station within the disposal site was identified. The similar release behaviour and supply rates for $\mathrm{Cd}$ across all 3 stations negates a driver of $\mathrm{Cd}$ remobilisation associated with disposal activities. The data presented here shows that the supply of metals to pore-waters and resulting sediment potential source or sink is a complex issue when trying to estimate the total supply from disposed sediments. Further work to improve understanding of the controlling factors of metal release to pore-waters would be beneficial in informing management decisions regarding these types of disposal sites.

\section{Acknowledgements}

This work was supported by Defra and MMO (contract E5403). We gratefully acknowledged the valuable contributions made by the scientific staff and crew of the RV Cefas Endeavour.

\section{References}

Bolam, S.G., Mason, C., Bolam, T., Whomersley, P., Birchenough, S.N.R, Curtis, M., Birchenough, A., Rumney, H., Barber, J., Rance, J., McIlwaine, P. \& Law, R.L.J., 2011. Dredged material disposal site 


\section{ICHMET 2012}

monitoring around the coast of England: results of sampling (2010). SLAB5 Project Report, Cefas, UK.

Davison, W., Fones, G.R., Harper, M., Teasdale, P., Zhang, H., 2000. Dialysis, DET and DGT: in situ diffusional techniques for studying water, sediments and soils. In: Buffle, J., Horvai, G. (Eds.), In-Situ Monitoring of Aquatic Systems: Chemical Analysis andSpeciation. IUPAC. Wiley, New York, pp. 495-569.

Mason, C. 2011. NMBAQC's Best Practice Guidance. Particle Size Analysis (PSA) for Supporting Biological Analysis. National Marine Biological AQC Coordinating Committee, 72pp, Dec. 2011.
Rabouille C, L Denis, K Dedieu, G Stora, B Lansard, C Grenz (2001) Oxygen demand in coastal marine sediments: comparing in situ microelectrodes and laboratory core incubations Journal of Experimental Marine Biology and Ecology, 285/286 pp. 49-69

Teasdale, P. R.; Hayward, S.; Davison, W. In situ, high-resolution measurement of dissolved sulfide using diffusive gradients in thin films with computer-imaging densitometry. Anal. Chem. 1999, 71, 2186-2191.

Verardo, D.J., Froelich, P.N., McIntyre, A. 1990, Determination of organic carbon and nitrogen in marine sediments using the Carlo Erba NA-1500 analyzer, Deep-Sea Res., 37, pp. 157-165. 